\title{
Geometrical analysis of architectural drawnings in the Shah-mosque Isfahan
}

https://doi.org/10.1515/cls-2020-0007

Received Jan 28, 2020; accepted May 03, 2020

\begin{abstract}
The golden number has been one of the most important measures of beauty from ancient Greece till now. Although the reason still unclear, it is certain that the golden ratio has a direct correlation with beauty. This nice feeling can come from listening to a musical piece or watching a visual art, which is based on this wondrous number. Although the golden number is more suitable from beauty or harmony's perspective, for some researches it is a requirement to develop Architectural designs. Therefore, in this article a masterpiece (Shah-mosque Isfahan) was investigated to find its golden relations. This mosque was chosen because of the precise and harmonious proportions. In this research: plan, sections, facade and decorations of ceiling tiles in main dome, were analyzed by Phimatrix software in which, existence of the golden ratio has been proven undoubtedly.
\end{abstract}

Keywords: architectural proportions; golden ratio; Shahmosque Isfahan; geometry; architectural design

\section{Introduction}

The essential and fundamental element of art, engineering art, and architectural engineering art, is geometry. In the legal space of geometry, everything such as components of a house or a city can be created and in masses of pluralities find their identity. Everything only via geometry, can find the limits and sizes it need to enter the universe, until based on itself with be placed in surface and spatial structures from the systems that include the environment [1].

\footnotetext{
*Corresponding Author: Masoumeh Goudarzi: Islamic Azad University of Boroujerd, Lorestan Province, Boroujerd, Iran; Email: mas.radmehr@yahoo.com

Mohammadreza Bemanian: Department of Architecture, Faculty of Art and Architecture, Tarbiat Modares University (TMU), Tehran, Iran

Mohammadreza Leylian: Department of Architecture, Islamic Azad University of Parand, Tehran, Iran
}

The architecture of Iran's past era has always been based on the use of geometry and methods of accurate sketching to the extent that awareness of the rules of mathematics and use of certain types of it was the duty of any architect and they were compared on this basis. It thus appears that geometry was very important in traditional Iranian architecture [2]. Thus one can regard the geometry as the hidden essence of architecture in different periods. Safavid era (1501-1722) for some reasons provided the foundation for an advanced architecture and the creation of world masterpieces. Safavids were the first Shiite independent government in Iran that immediately after stability, chose the language of science and art for their introduction. During this period, the knowledge of philosophy, along with the advent of great philosophers such as Mir-Damad and MullaSadra, made a lot of progress and this progress along with several reasons such as economic prosperity, religious beliefs, proper physical context (Isfahan city) and the special attention of the kings of this dynasty to development, has led to a great progress in architectural knowledge.

In the study of the application of geometry in architecture (statics or module and measurement), if we cannot show geometry in plan and section, we cannot say that we know it. At the higher stages the researcher should be able to design on this knowledge. Of course, designing here is not an inappropriate conversion of several elements of the design. This design requires the correct identification of the geometric elements at different levels and the position of each element in the design, the understanding of the relationships between them, the techniques of composition and their meanings. However, today, the basics (mystical, statics or module and measurement) of geometry have been replaced with new foundations, but the recognition of those bases and traditional uses in studying the works of traditional architecture and gaining a comprehensive understanding of their design is necessary.

Tahbaz in an article titled "The sacred shape" by introducing basic geometric shapes which containing ratios: $\sqrt{ } 2, \sqrt{ } 3, \sqrt{ } 5$ and $\varphi$, calls the forms of the combination of these numbers "sacred form" and finally it is emphasized on the necessity of searching for rules on the proportions of Islamic art and architecture in Iran [3]. The present re-

๑ Open Access. (c) 2020 M. Goudarzi et al., published by De Gruyte 
search tries to use the descriptive-analytical method to collect theoretical foundations, and then analyze the plan, sections, facades and decorations of the Shah-mosque in Isfahan, by using the Phimatrix mathematical software. This program gives us analyzed geometrical shapes from a picture based on golden proportions. Therefore, it can be possible to examine our supposition which says that the building is organized according to the principle of proportionality. In order to improve the credibility of the research, the original schemes of the plane and section, obtained from "Cultural Heritage Organization of Iran", have been analyzed in this research.

\section{Background}

So far, a lot of research in geometry and proportions has been accomplished that can be briefly described in the works of former Soviet scholars such as: Geometric analysis from Bolatov on the tomb of Qatluq Agha in Samarkand; Mankofskaya on the Tomb of Khajeh Ahmad Yusawi and central Mosque in Samarqand; and Donald Wilber on the Goharshad School in Herat of Central Asia; which focused specifically on Timurid and Ilkhani periods [4]. Other studies include: "Hidden Geometry in the elevation of Shaykh Lotfollah mosque" by Kambiz Haji-Qasemi [5]; "chahartaqi of Niasar" from Hardy [6]; "Tabriz Kabood mosque" by Mojtaba Ansari and Ahad Nezhad-ebrahimi [7]; and "Palace of the Sun" by Mojtaba Rezazadeh-Ardebili and Mojtaba Sabetfard [8].

Indeed, less researches have done enough study to specifically trace the golden ratio in Iranian-Islamic architecture. Ziainia and Hashemi-zarjabad said that Safavid architects (during the first restoration period) had a full awareness of the golden ratio and its application in creating beauty before viewers' eyes [9].

\section{Geometry in ancient architecture}

Any physical being is characterized by its size. It means that the universe has been created based on geometry. Therefore, geometry is inherent a quality before it could be a quantity [10]. But in the past geometry has flown from the rank of a material quantity to a semantic quality and these quantities are secrets from the cosmos [11]. They thought that an incorporeal world is looking for a pattern in order to people can touch it; and this pattern is geometry. Plato introduces geometry as the clearest form of language which can describe territory of universe [12]. He was so in- terested in geometry to the extent that he knows it as a spiritual quality; hence: "it is an innate matter from the Ideas world that we are inherently familiar with" Plato said. This way of thinking about geometry is why architects have always looked at it as a code, when referring to their immaterial purposes.

An extraordinary use of geometry can be seen in Iranian Islamic architecture. Persian Muslim architects used this innovative tool to give assurance that beauty and usefulness were observed in the building. They also embodied the notion of plurality in the same unity. It meant: "the belief in monotheism" which was rooted in the abstract of the teachings of Islam. The result of this ideology was coherence of components, proportionality, order, and harmony of the whole. The geometric analysis of many Iranian monuments has proven that they used the full knowledge of proportions, especially the golden ratio, has been widely utilized; and it was the basis of aesthetics for them [13]. Geometry in Islamic architecture determined many things. The principles cited in relation to geometry included almost all the principles of this kind of architecture. In the architecture of some nations, geometry and proportion, especially its golden form, have been used more or less, but for each to a certain extent and in a special meaning. For example, in ancient Greece, when the focus was on the human, geometry has been used in architecture and other arts based on Humanism. But in the Islamic architecture, it was entirely sacred (to the kingdom of heaven), and the material components and their connected meanings - in a beautiful and coherent manner- reached to the God and melted in him. Islamic architecture was able to use geometry as its symbolic language format. Among the examples of Iranian Islamic monuments, Safavid masterpieces have many mysteries features and among them the Shahmosque has very strong and complex proportional combinations.

\section{Golden ratio}

We have some numbers to understand the physics of the universe such as the Planck constant, $\mathrm{Pi}$, and the gravitational constant, but what is certain is that - at least to the best of our knowledge - the world cannot be understood without these numbers. The mathematical concepts that are precisely defined by a number are clearly visible in the universe and in some way established the balance of the universe. One of these numbers is a unique constant called the golden ratio. If one divides a line into two unequal parts, and the proportion of the larger part to the 


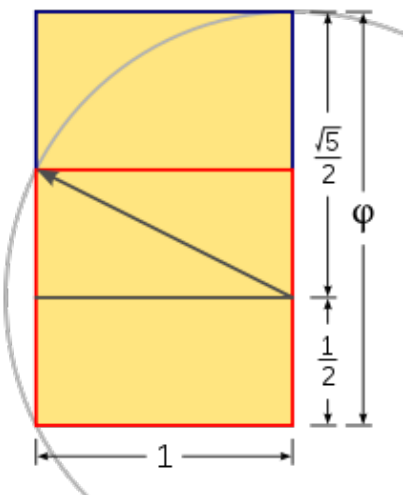

Figure 1: Inner divisions of a Golden rectangle

smaller part be equaled to the proportion of the sum of two parts to the larger part. One can tell that line is divided from its golden point. The golden ratio symbolizes the rebirth and the progression and expansion of the unit [14]. We show the golden ratio with the Greek letter $\varphi$. Phi is an irrational number and the ancient Egyptians have discovered it. They had taught this proportion to the Greeks, and the golden ratio became very important for the Greeks. They could have created two halves of a statue by two different artists based on full-scale golden proportions, then two halves matched eventually [15]. Euclid, in the book of Principles, defined it as follows:

$$
\varphi=\frac{1+\sqrt{5}}{2}=1.6180339887
$$

Phi is the first letter of the name Phidias who was a great sculptor in ancient Greece. Probably he considered the golden ratio - before Euclid - in his artistic manner. Italian mathematician, Luca Pacioli called this numerical ratio divina proportione as a title for his book. And German mathematician Martin Ohm called it the golden ratio.

\section{Shah-mosque in Isfahan}

Shah-mosque is the most important historical mosque in Isfahan that was built during the Safavid period and on the orders of Shah Abbas I. Construction of it began in 1611 and completed in 1629. It created by Ali Akbar Isfahani who was one of the greatest architects in Iran [16]. This building represents the peak of one thousand years building mosques in Iran. Bulky parts of the building and their decorations in this mosque are magnificent and superbly matched together which makes it one of the best in the world [17].

\subsection{Analysis of the proportions in the mosque}

In many Iranian buildings, plan and section were designed in a framework of squares and equilateral triangles due to their junctions could determine all of the important points (such as the width and height of the doors, the width, length and height of the hall, the location of the inscriptions, and so on). Therefore, the size of each part was related by a certain proportion to other parts. As a result, building was not a collection of non-conforming components; but it was a Harmonious combination from parts with proportionate communications which makes that place to be lively and soothing [18]. The software analysis of plan and sections of the Shah-mosque indicates the special importance of golden proportions for its architects during design process.

\subsection{Plan analysis}

Six golden rectangles are identifiable in the plan. They are examined for their internal proportions. Main golden rectangle is related to the eastern part (Figure 2). An analysis of this golden rectangle shows that golden distances stay on main lines of the plan (main divisions of space) and the central point coincides with the altar. Red circles indicate important joint points between plan and analysis.

In the next analysis, golden rectangle is considered horizontal and in the north part of the plan. (Figure 3) It shows that all main lines of the plan are separated by golden distances. Dimensions of the northern rectangle are nearly equal to the eastern rectangle. The most important line between building and yard is separated by golden pro-

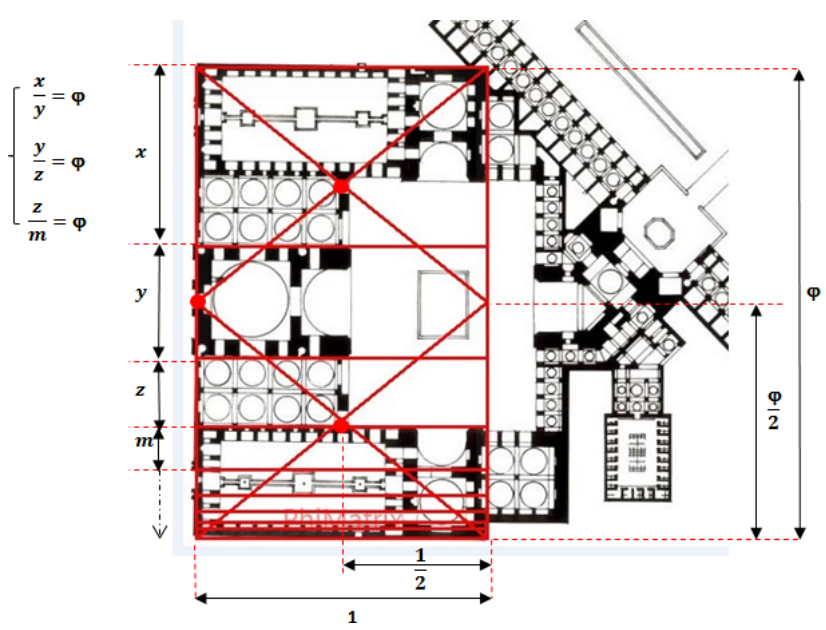

Figure 2: Adaptation of plan lines with golden distances in the eastern frame 


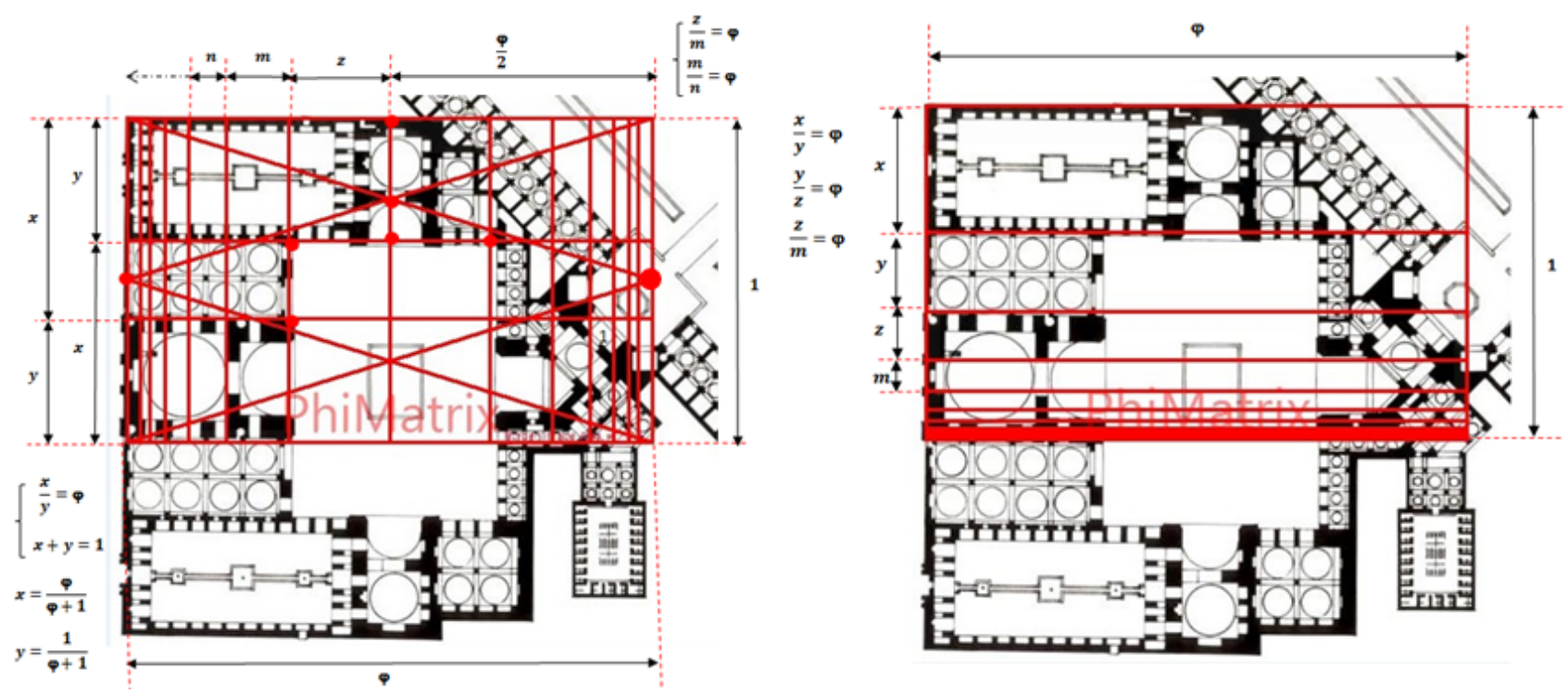

Figure 3: Adaptation of plan lines with golden distances in the northern frame
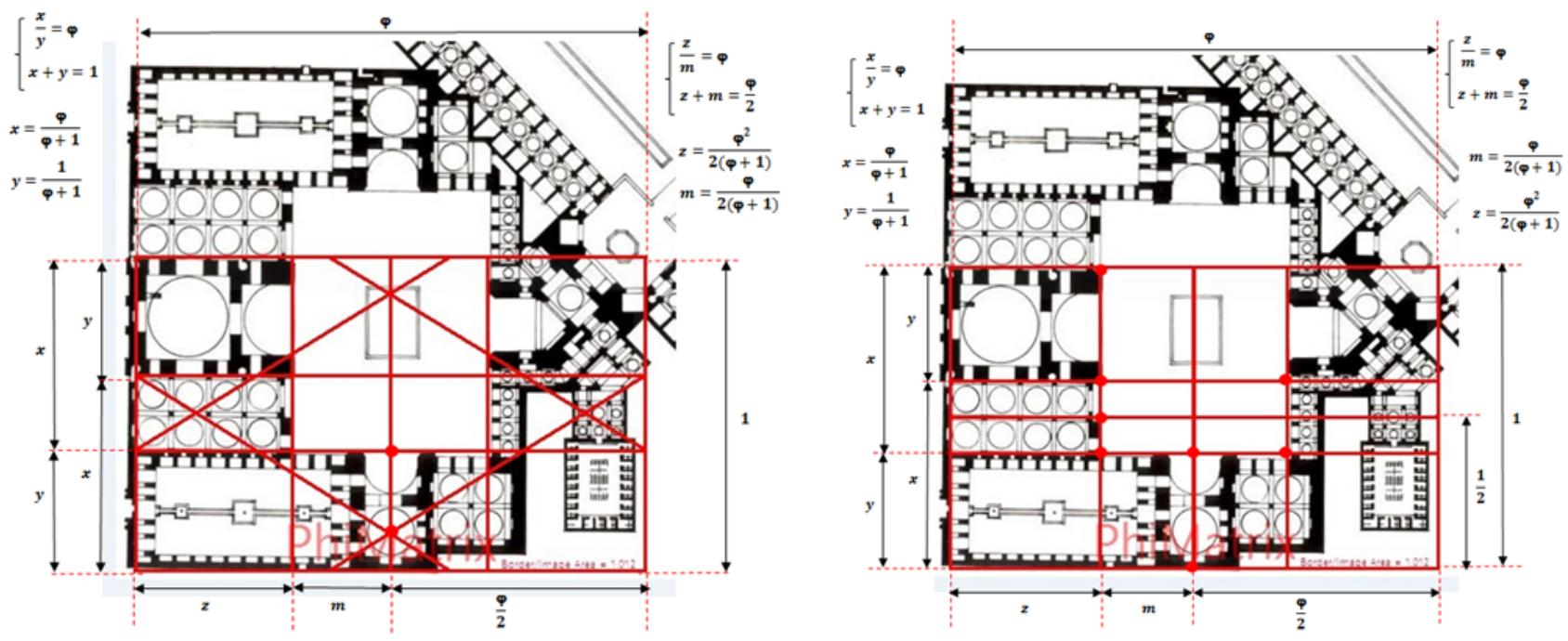

Figure 4: Adaptation of horizontal and vertical divisions of the southern plane with Golden distances

portion, also midpoint in left-hand side stay on the main entrance of the building (from Naghsh-e-Jahan Square). These adaptations are organized accurately. Due to the symmetry of the plan, similar analyzes could be obtained by the southern part (Figure 3).

In the next rectangle (southern), two sides of the main porch have been separated from the yard by golden ratio. It means the main walls are located in golden distances. Two other junctions stay on centers of minor southern porch (entrance and dome) (Figure 4).

Next supposed rectangle is in the middle and ends up along main entrance in the turning of plan (mosque plan turns in the entry porch). Two golden middle lines in the right figure coincide with walls of entrance and main porch. Furthermore, they cross from near the edges of pool. There is a junction in the main door of main dome and two other junctions in the edge of two (northern and southern) main halls in the midpoint of phi side of golden rectangle (Figure 5).

Fifth rectangle is related to the original space which includes below the main dome and seraglio. This is the most important part of mosque and could be named as the guest space. The picture shows accurate adaptation of this part with a golden rectangle. Also junctions stay on two main sides of entrance and dome. Indeed, side walls of the main porch have been separated from the sides of the main yard with the golden ratio that means main walls 

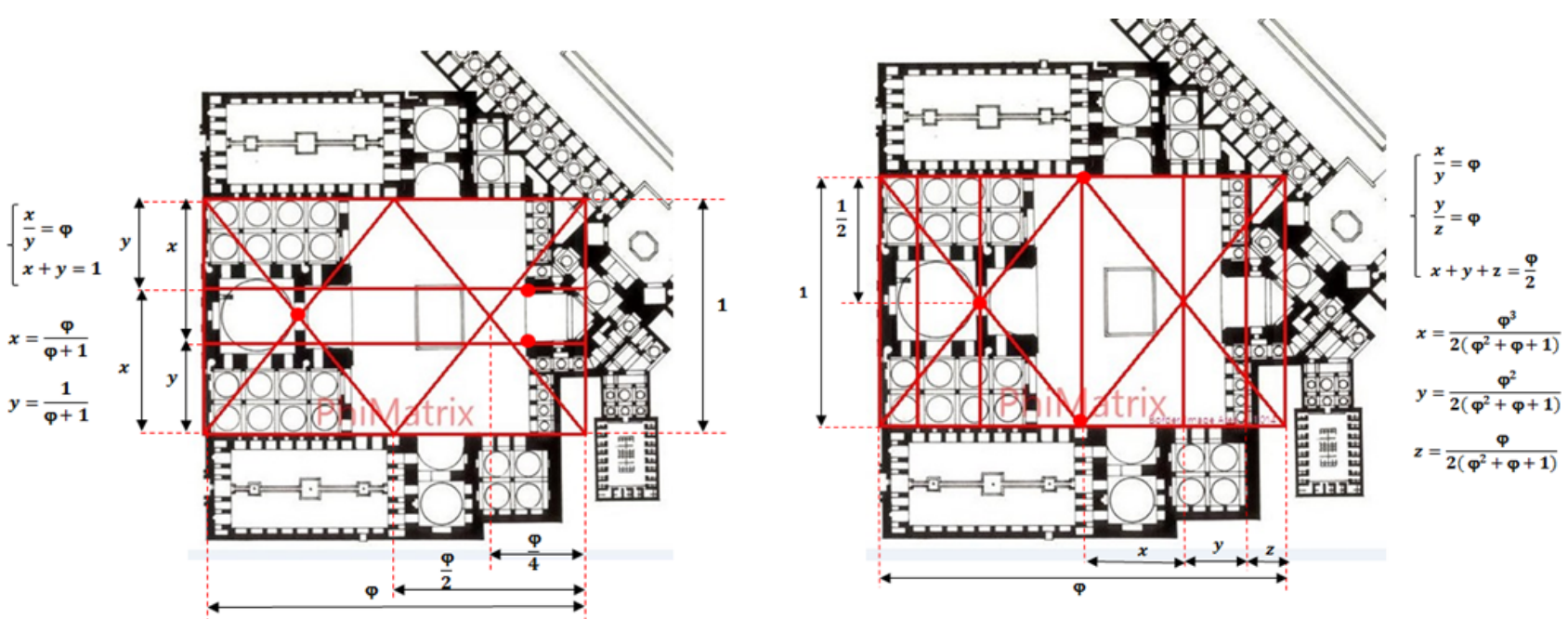

Figure 5: Adaptation of horizontal divisions of the middle golden rectangle with walls of two main entrances

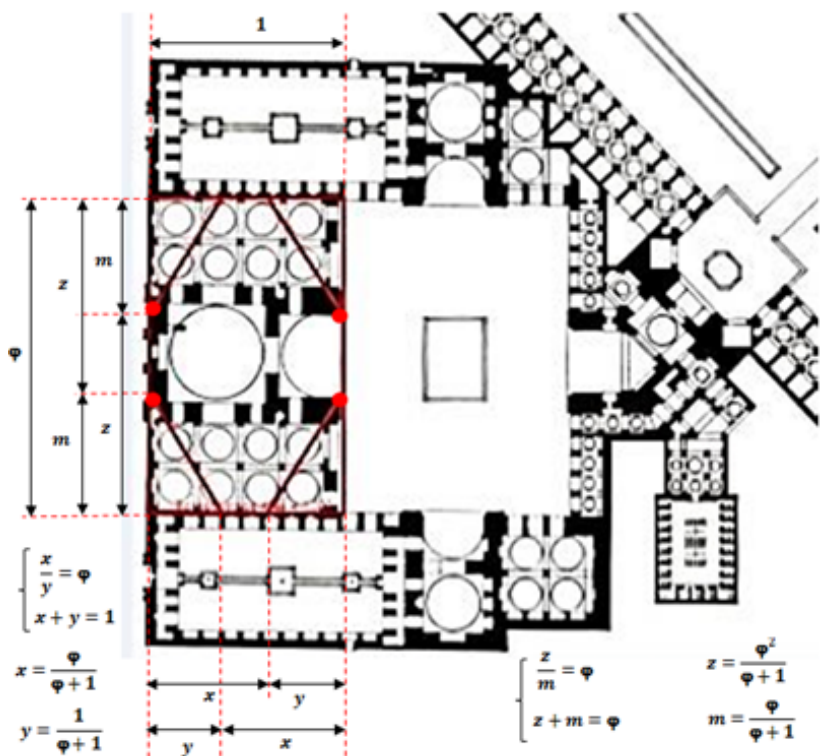

Figure 6: Adaptation of the space below the main dome with a golden rectangle and the separation walls on the golden distances

of this entrance are located in golden distances with yard space (Figure 6).

The yard (including its porches) is located in a golden rectangle likewise. Interestingly, the pool range has been created from both horizontal and vertical sides in intersection of golden lines. Furthermore, span of these lines stay on four porch-openings (Figure 7). Stierlin believed that all sizes in the Shah-mosque, is a submultiple of pool dimensions [19]. Perhaps a particular attention to the pool represents a meaningful connection between this building and water.

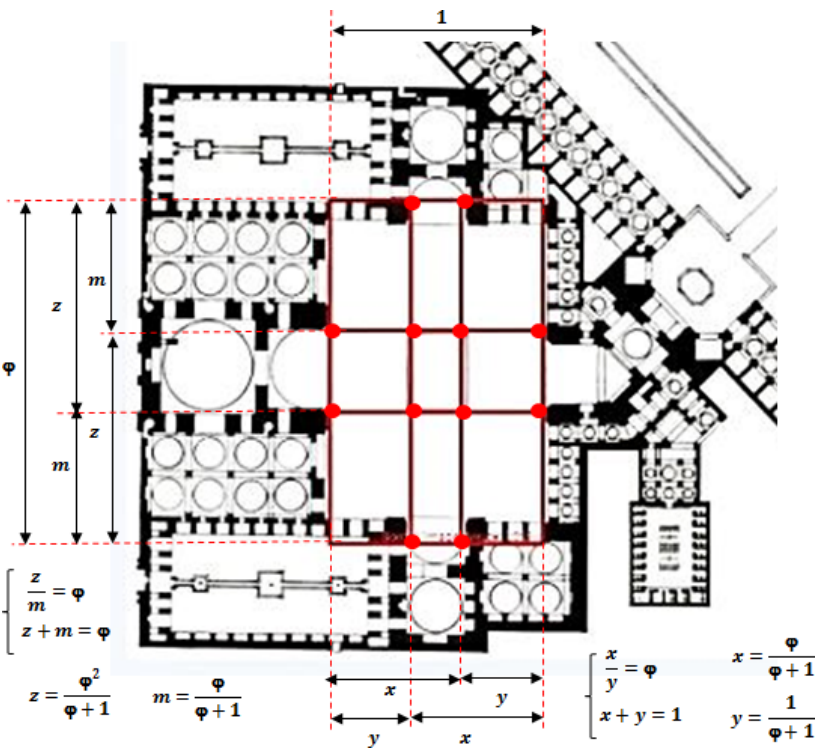

Figure 7: Setting the yard and porches in a golden rectangle

\subsection{Section analysis}

One of the most difficult stages in architecture designing is section planning according to the concept. In the point of architectures view, for a perfect building, sections must be planed such as plan and facade. It means events that occur in the section of a building should be planned and this planning should be in full compliance with the original idea. Section analysis in the Shah-mosque shows that the architect certainly looked at the frame and the sky line; but what distinguishes this masterpiece is high grade of discipline in its entire design. There is nothing without reason or explanation in the whole building. The section anal- 
Table 1: Result of plan analysis

\begin{tabular}{|c|c|}
\hline Range of study & Obtained golden proportions \\
\hline \multirow[t]{2}{*}{ 1-Main part } & Staying on golden distances and main divisions of spaces. \\
\hline & Coincidence of central point with the altar. \\
\hline \multirow[t]{2}{*}{ 2-North part } & Accurate matching of two main walls with horizontal golden distances. \\
\hline & $\begin{array}{l}\text { Accurate matching of golden vertical distances with separating walls of yard (main lines of the } \\
\text { plan). }\end{array}$ \\
\hline \multirow[t]{2}{*}{ 3-South part } & Accurate matching of two main walls with horizontal golden distances. \\
\hline & $\begin{array}{l}\text { Accurate matching of golden vertical distances with separating walls of yard (main lines of the } \\
\text { plan). }\end{array}$ \\
\hline 4-Middle part & $\begin{array}{l}\text { Accurate matching of main lines with golden lines (symmetrical). } \\
\text { Placing two corners of the yard between golden points. }\end{array}$ \\
\hline \multirow{2}{*}{$\begin{array}{l}\text { 5-Main seraglio } \\
\text { (guest space) }\end{array}$} & Accurate adaptation of main Prayer room with golden rectangle. \\
\hline & Separation of main wall of the dome with golden ratio. \\
\hline \multirow[t]{2}{*}{ 6-Yard } & Adaptation of the yard including porches in a golden rectangle. \\
\hline & The exact position of pool between four internal golden lines. \\
\hline
\end{tabular}
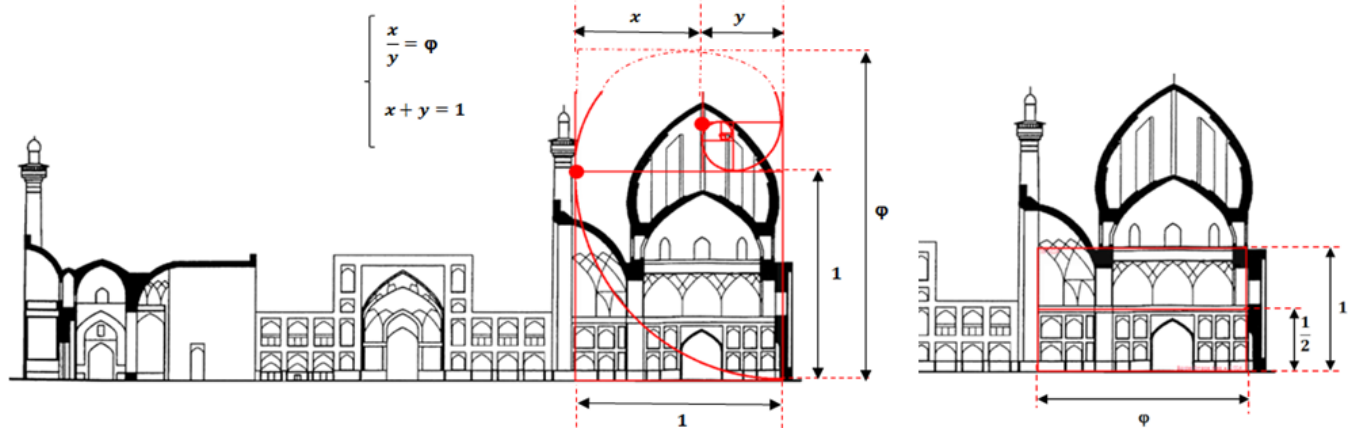

Figure 8: Golden rectangles pass from the main dome and important points adapt with golden dividing lines

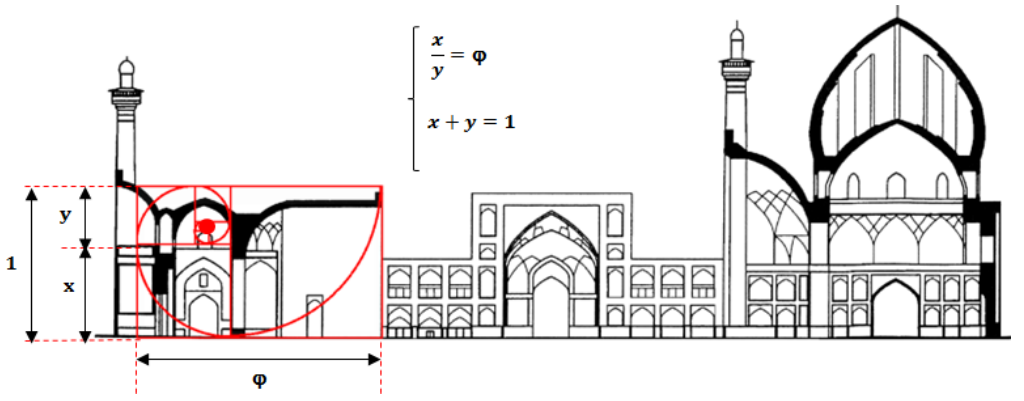

Figure 9: Adapting the smaller section with golden rectangle

ysis shows the presence of golden ratio in this building at an excellent level.

Main dome section can be imagined between two golden crossover rectangles (Figure 8). One of them matching with dome (imaginable space from dome to finial) and one of them can be supposed in space below it. The golden dividing point is calculated in top rectangle. It located on curvature point of dome and also passes from the tip (middle of dome). Horizontal rectangle is divided to two equal parts. Dome arc is approximately parallel with golden spiral arc and the starting point of finial-head is separated by golden ratio.

The smaller part of this cut is also stands completely in the golden rectangle. The main lines separating spaces and the roof are also aligned with golden dividing lines. Furthermore, the final point lies around the middle of the smaller dome (Figure 9). 


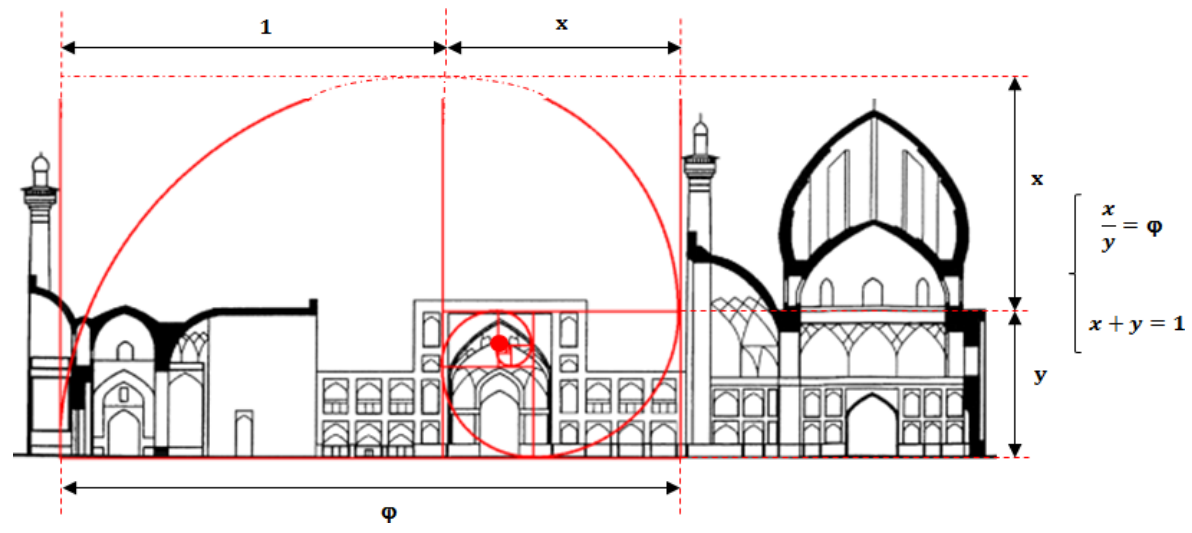

Figure 10: Abstract frame between two finials adapt with golden rectangle

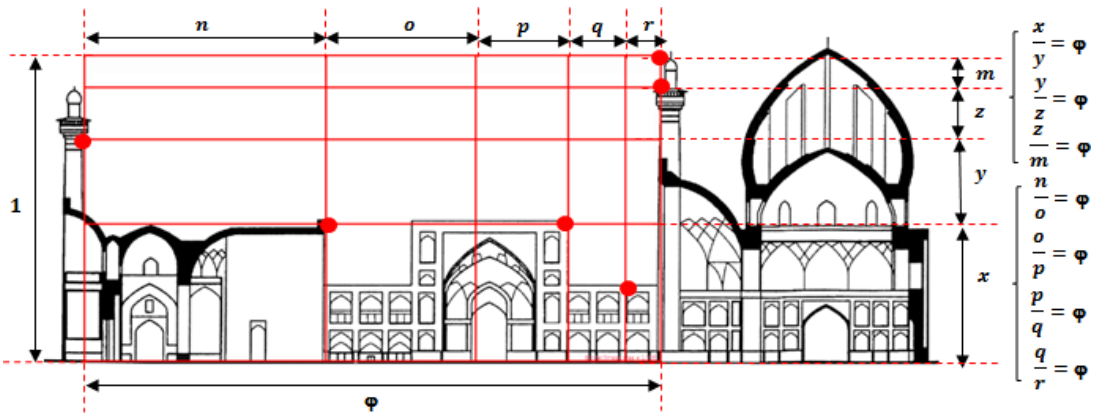

Figure 11: Abstract frame between two finials (left-side of north-south section) adapt with Golden rectangle
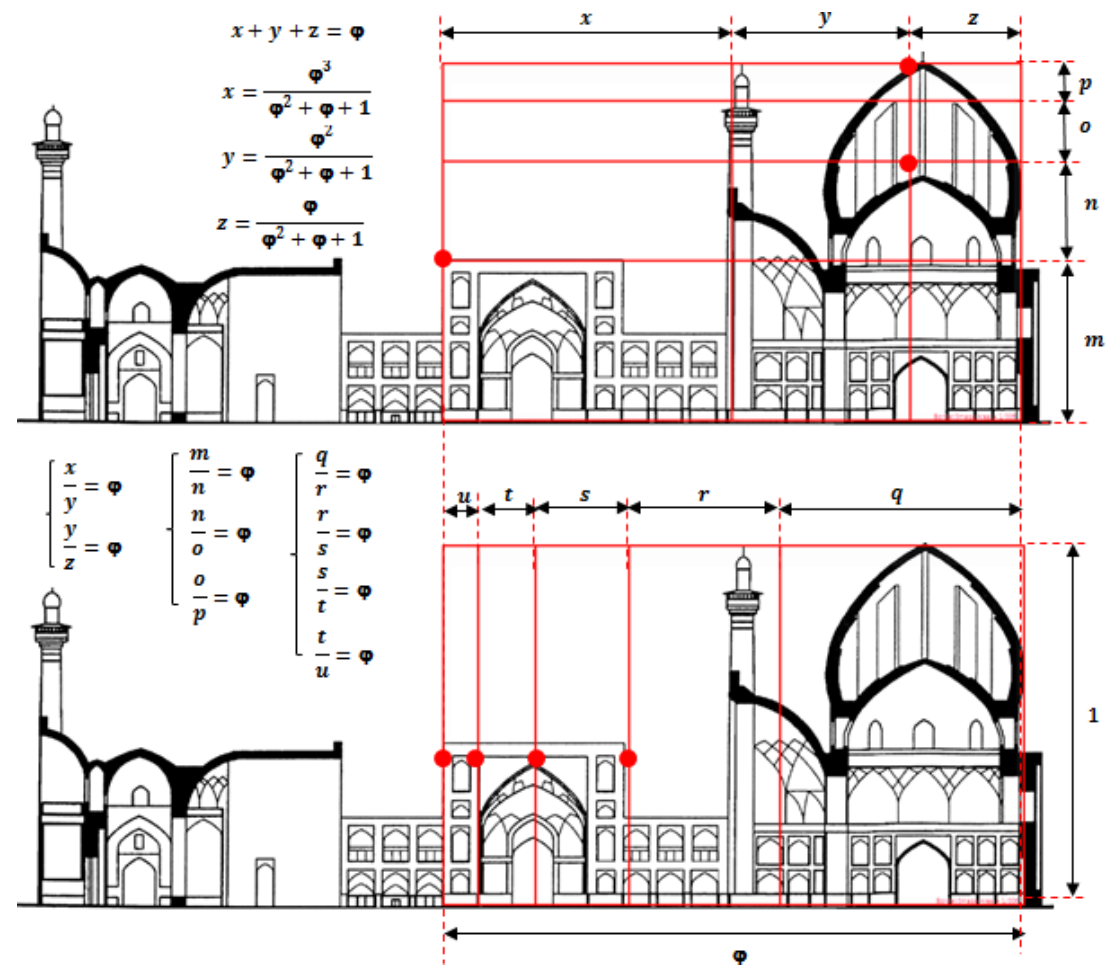

Figure 12: Abstract frame between two finials (right-side of north-south section) adapt with golden rectangle 


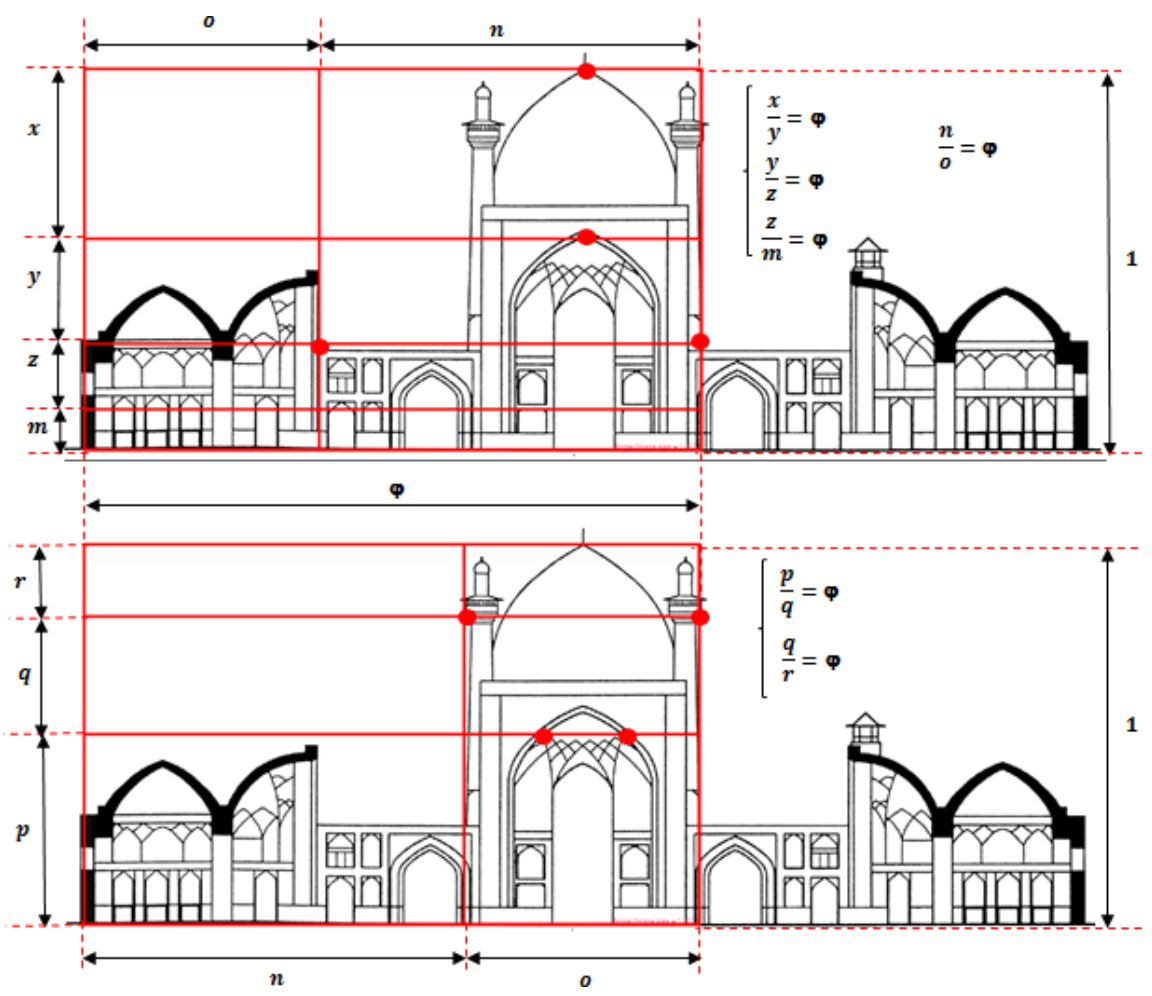

Figure 13: Abstract frame between two finials (left-side of east-west section) adapt with golden rectangle
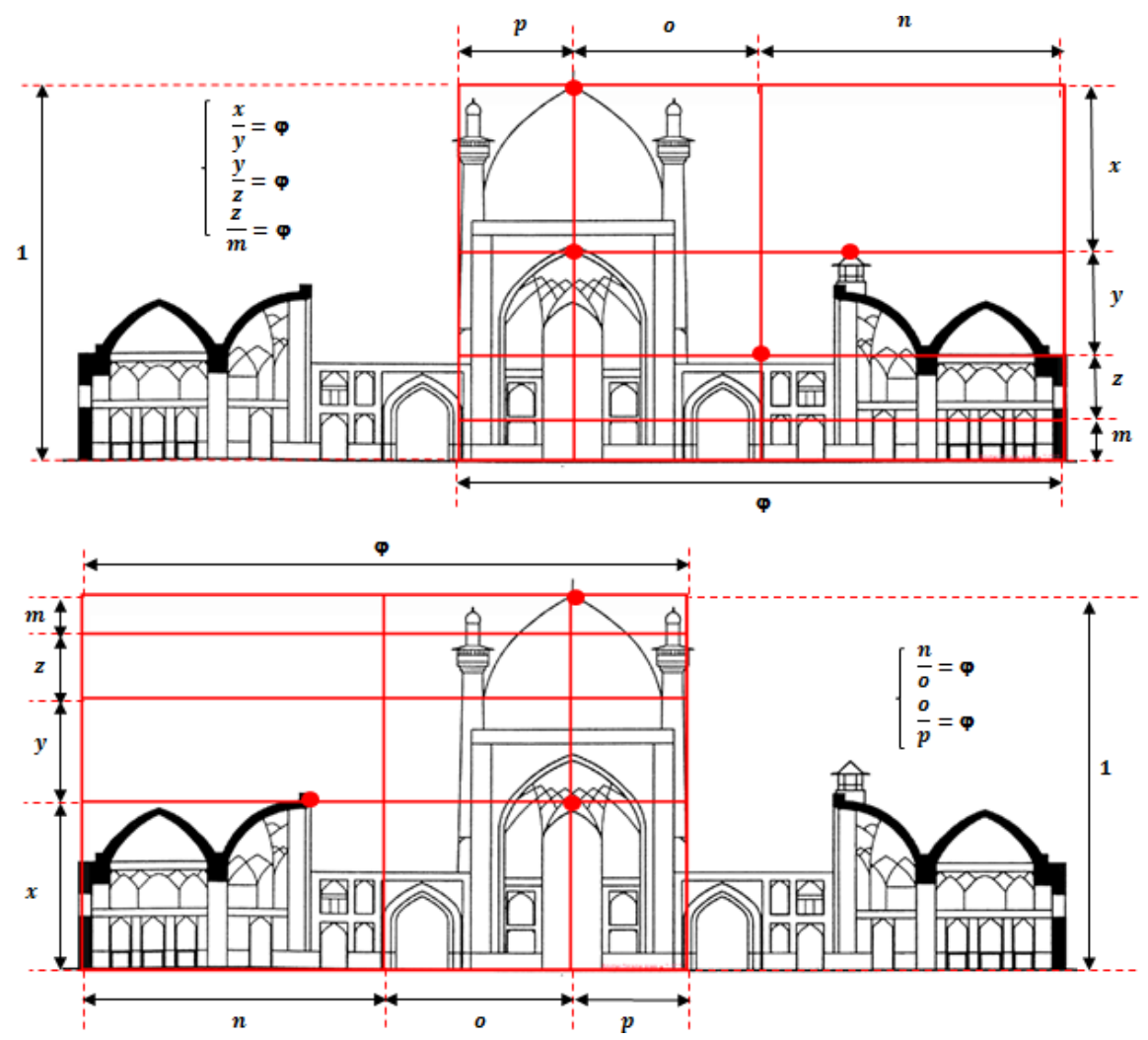

Figure 14: Comparing between two similar abstract frames 


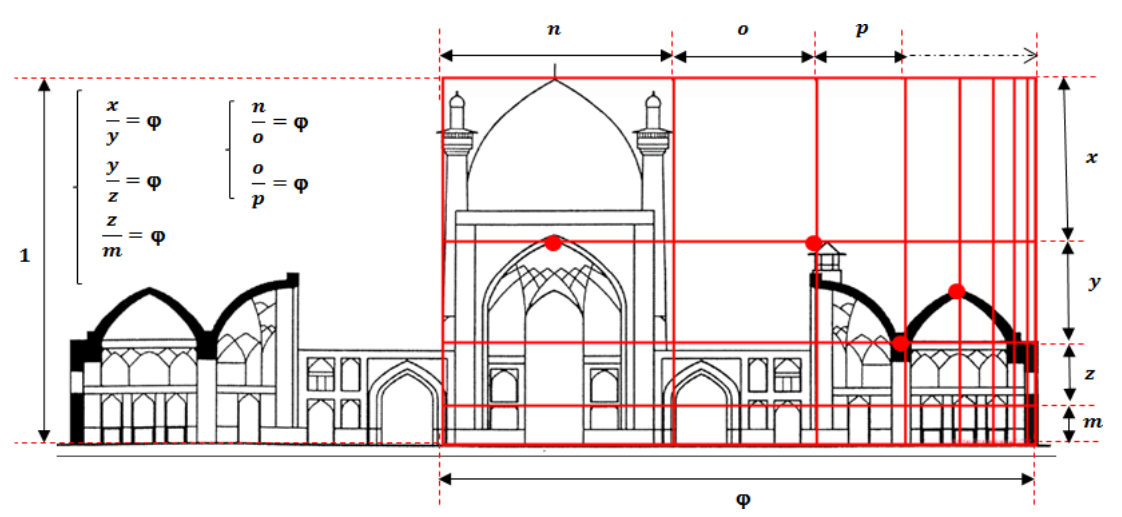

Figure 15: Adaptation of vertical gold lines with important points

Table 2: Result of the section analysis

\begin{tabular}{cl}
\hline Range of study & Obtained golden proportions \\
\hline Main dome section & Two golden crossover rectangles \\
& Adaptation of curvature point of dome and tip with gold proportions. \\
& Being approximately parallel between dome arc and golden spiral. \\
& Separating curvature point of dome and the starting point of finial-head by golden ratio. \\
& Evaluated abstract frame. \\
Entrance & Accurate matching of the entrance section with a golden rectangle. \\
& Adaptation of main line (main wall) with golden split line. \\
& Starting the arc of porch, from golden point. \\
& Adaptation of four abstract frames with golden rectangles. \\
& Separating porches and finials (adjacent the dome) from the golden point. \\
& Being approximately parallel between dome arc and golden spiral. \\
& Adaptation of six important points with golden distances in left-side of north-south section. \\
& Accurate divisions of section based on gold number. \\
& Adaptation of vertical gold divisions with important points of subsidiary porch facade. \\
& Adaptation of tip (in the main dome), top of main porch, sky-line of side-porches, beginning \\
& line of head-finials and dividing line of subsidiary porch with golden distances. \\
& Adaptation of roof in subsidiary porch and dividing line of side-porches with golden lines. \\
& Adaptation of vertical golden lines with some important points. \\
\hline
\end{tabular}

The next analysis shows the abstract frame between the two finials, which perfectly matches with golden $r a-$ tio. Also the spiral arch is parallel with dome arch and final spin point of golden spiral is located on the porch (Figure 10).

The eight following pictures also examine the abstract frames in two main sections of the mosque.

In the left-side of north-south section, span between two finials (they belong to two different pair of finials) stay on golden rectangle accurately and six important points adapt with golden distances (Figure 11).

There is also another abstract frame in the right-side of the north-south section which indicates accurate divisions of the section based on the gold number. As it can be seen, the roof of the subsidiary porch and the edge of the finial are in alignment with and in gold distance to the ground (In association with abstract frame). The vertical gold divisions also adapt with important points of the subsidiary porch façade, and the middle of the dome stays around the gold line (Figure 12).

In the following pictures, the abstract frames of the east-west sections are analyzed. These five pictures would obviously show the accurate adaptation of the section with the golden lines.

Top of the main dome, top of the main porch, the skyline of the side-porches, the beginning line of the headfinials, and the dividing line of the subsidiary porch are all precisely aligned with each other and within golden distance from one another (Figure 13) 
In the next picture, proportions of the left-side and the right-side are compared. They look alike and symmetrical with minor differences. Head of the subsidiary porch and the dividing line of the side-porches also remain in golden lines (Figure 14).

The last section analysis indicates that the vertical golden lines are in accordance with some important points. These proportions can be obtained from other side similarly (Figure 15).

\subsection{Facade analysis}

Facade is one of the most important resultants of architectures mission. They introduce the result of coordination of the whole (technical and aesthetic) in the facade.

There are different aspects of their works (in a concept that is identified with the general form of the building) for observers. In other words, facade is a dress which building is worn and can indicate personality, morale, style, social
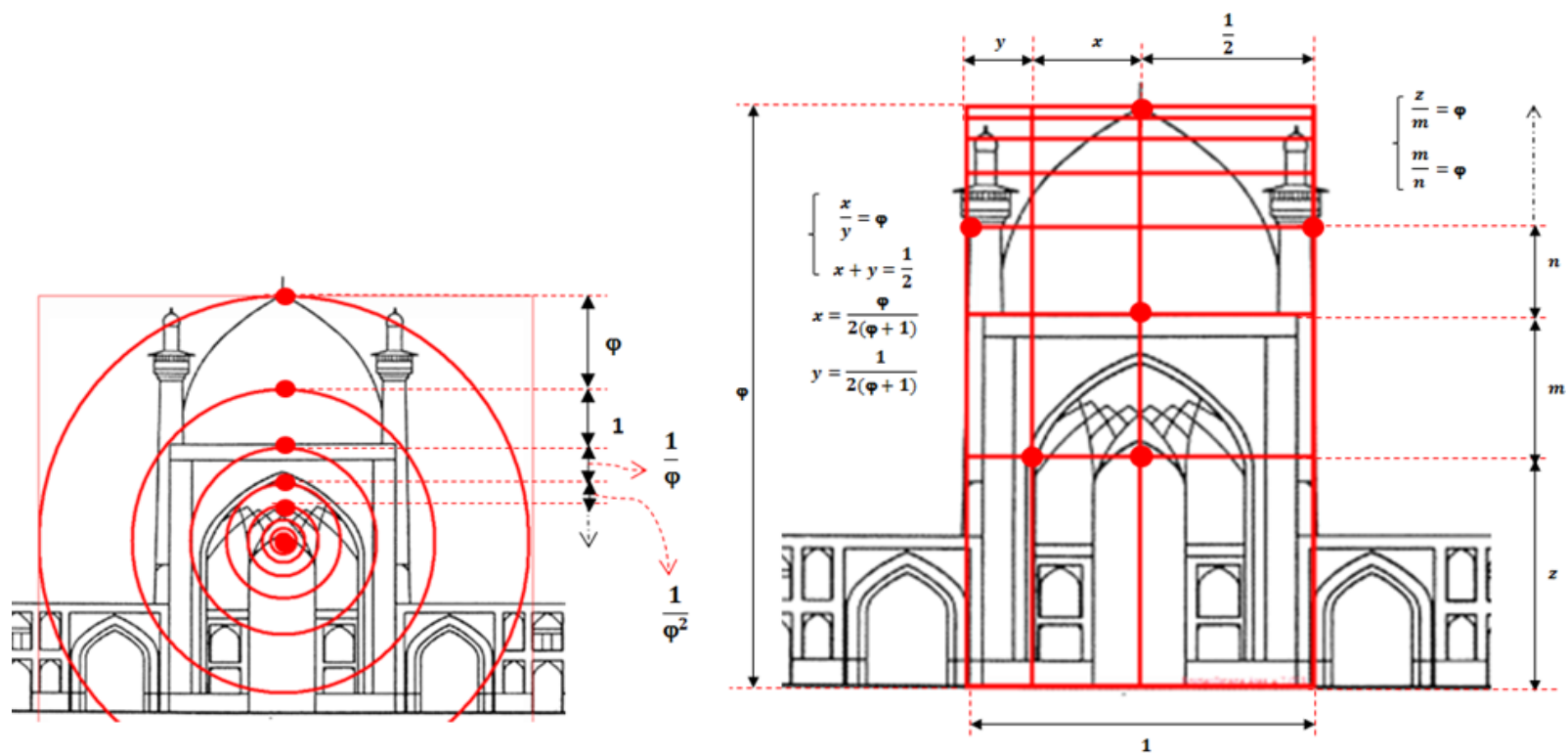

Figure 16: Placing main dome with main porch in golden rectangle; (right pic) and adaption tips of dome, finials, porches, and the shoulders of the main porch, with golden distances
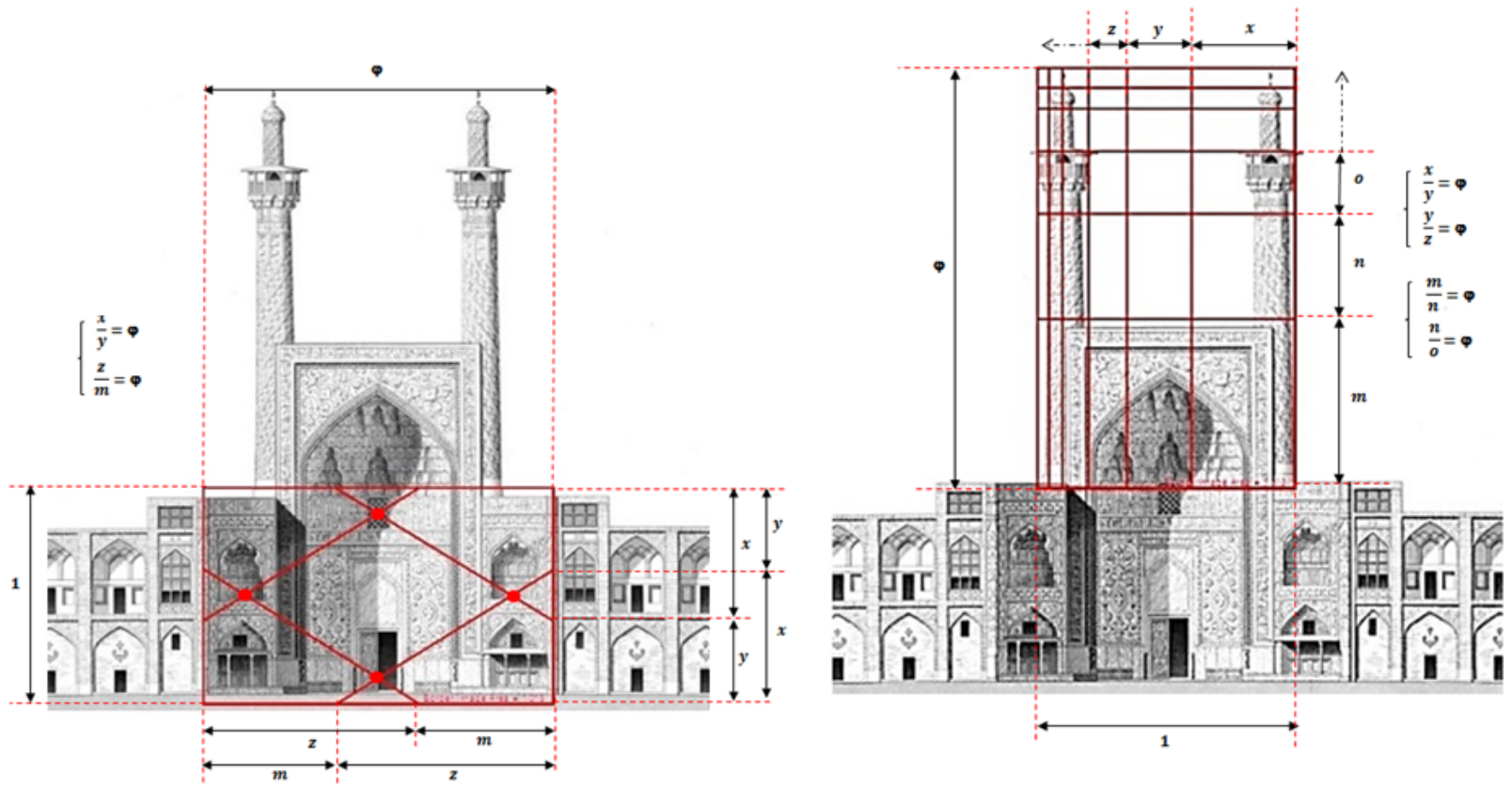

Figure 17: Dividing entrance porch into two golden rectangles 
Table 3: Result of facade analysis

\begin{tabular}{|c|c|}
\hline Range of study & Obtained golden proportions \\
\hline $\begin{array}{l}\text { Main dome and main porch } \\
\text { (internal facade) }\end{array}$ & $\begin{array}{l}\text { Placing the dome and finials in a golden rectangle. } \\
\text { Evaluate abstract frame. } \\
\text { Adaptation of important points with golden circles. }\end{array}$ \\
\hline $\begin{array}{c}\text { Main entrance (external } \\
\text { facade) }\end{array}$ & $\begin{array}{l}\text { Placement of vertical rectangle in a golden rectangle (from sky-line) } \\
\text { Precise splitting from ceiling of the porch. } \\
\text { Adaptation of horizontal rectangle with its main sides. } \\
\text { Adaptation of horizontal golden lines with division lines of facade in vertical rectangle. } \\
\text { Adaptation of golden junctions with important points in horizontal rectangle. }\end{array}$ \\
\hline
\end{tabular}

Table 4: The result of analysis of decorations

\begin{tabular}{cl}
\hline Range of study & Obtained golden proportions \\
\hline tiling under the dome & Conformity of dividing lines in ceiling tiles with golden distances between golden circles. \\
\hline
\end{tabular}

class, culture and economic conditions. Facade analysis in Shah-mosque, tells us that designers have calculated its proportions meticulously.

In the first analysis of the facade, we consider the entrance porch up to the tip of the main dome which is placed in a golden rectangle (Figure 16). It can affirm the importance of designing these abstract imaginary frames for designers. It seems as though they considered and calculated these invisible spaces the same way they did the more visible spots.

Another analysis can be obtained by passing the gold circles. As it can be seen, all important points and tips in the facade are perfectly located within the distances among the golden circles (Figure 16).

Similar to the plan that was divided into interwoven golden rectangles, the main entrance porch can be divided into two golden rectangles which do not overlap. These two horizontal and vertical rectangles are determined by two portions of the entrance porch that are separated in skyline, sides of the finials and sides of the fovea-shaped space of the entrance. In the vertical rectangle, the two finials (from down to top) are matched with the surrounding golden rectangle. The horizontal rectangle also has similar proportions. The unique tile of the mosque is located on the dividing line between the two golden rectangles. The horizontal golden lines in the above rectangle, adapts with the division lines of the façade; and the golden junctions are located on important points, under the rectangle (Figure 17).

\subsection{Analysis of decorations}

Analyzed picture shows the tiles under ceiling of main dome. As it can be seen, separation lines conform with distances of golden circles (Figure 18).

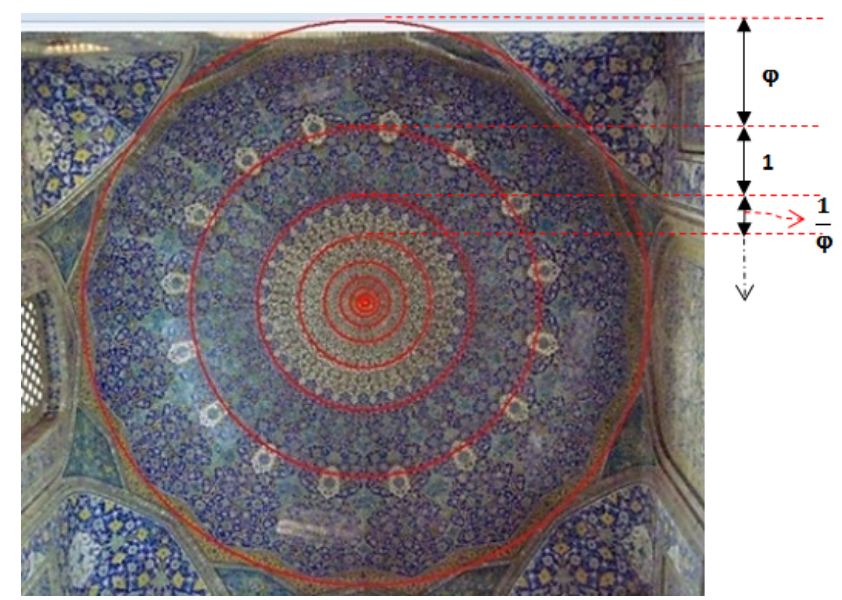

Figure 18: Conformity of dividing lines in tiles, with golden distances between golden circles

\section{Conclusions}

Geometrically, the Muslim architect evolves along with its work and perhaps, geometry is the only unique science, common between engineering, aesthetics, and symbolic aspects. An architectural work is in its best shape when its aesthetic and technical dimensions interact with each 
other and no dimension supersedes the others. From this point of view, it might be said that the reason for creation of the imperceptible masterpieces such as Shah-mosque was the mastery of their engineers and architects in geometry and the principle of proportionality. Inspired by the full respect for the golden proportions in the creation of God, they put the golden ratio as their original pattern. At first, they tried to express the importance of golden proportion in aesthetics, because the entire structure of this research is based on this principle. In this case, it is safe to say that the Shah-mosque is a unique masterpiece in Iranian architecture in terms of golden proportions. Considering that the architects of this building had done such complex calculations in different layers by basic tools and without any technological help, make us astonished.

The software analysis of this mosque, include very interesting and surprising results from golden proportions which is hard to imagine that human beings with the capabilities of those living four hundred years ago could make it happen. Although some architects may think that the main hall way and its curved entrance which are designed according to face Gheblah, is the most important geometrical feature of Shah mosque; this advanced study has proved a deeper and more precise architecture which is based on geometry in all aspects.

In the pictures analyzed in this study, the golden ratio is vividly present in the plan, section, facade and decorations of the mosque. The architecture of the Shah-mosque in this regard, differs from the other buildings in that everything is calculated in all aspects of its design. In this mosque, we are faced with a thoroughly accurate construction. This subject is evident more and better in the analysis of plan and section. This volume of calculation and accuracy means that its architects had a great deal of respect for its residents and viewers.
[2] Molavi B., Investigating the application of geometry in the past architecture of Iran, Building and Housing Research Center, Tehran, Iran, 2002.

[3] Tahbaz. M., The sacred shape, Soffeh, 2004, 38, 12-25.

[4] Golombek L., Wilber D., Timurid architecture in Iran and Turan, Cultural Heritage Organization, Tehran, Iran, 1995.

[5] Hajighasemi k., Hidden Geometry in Sheikh Lotfollah Mosque View, Soffeh, 1996, 21, 28-33.

[6] Godard A., Works of Iran, Astan, Mashhad, Iran, 2009.

[7] Ansari M., Nezhad-ebrahimi A., An Investigation on the Historical Course of Setting up Proportion Systems in Architecture with Emphasis on Aesthetic, Moon Art Book gournal, 2011, 151, 46-57.

[8] Rezazadehardebili M., Sabetfard M., Recognition of the Application of Geometric Principles in Traditional Architecture,Fine Art, 2012, 18, 29-44.

[9] Ziyaeiniya M.H., Hashemizarjabad H., Golden ratio and Iranian Islamic Proportional Systems in Qa'en central Mosque, Iranian Architectural and Restoration, 2016, 11, 89-100.

[10] Nadimi H., The truth of the design, Letter of the Academy of Sciences, 1999, 14, 19-34.

[11] Sadati N., A Comparative Study of Geometry between Iranian Painting and Cubism, Art moon book gournal, 2009, 136, 88-91.

[12] Lauer R., Sacred geometry, Institute for Cultural Studies and Research, Tehran, Iran, 1989.

[13] Alipour R., Dehar A., Geometrical analysis of architecture of Sheik Lotfollah Mosque to find the geometrical relations between its prayer hall and the entrance, Bagh-Nazar, 2013, 26, 33-40.

[14] Fatemimoghareh Sh., Fundamentals of Holy Geometry in Traditional Art. Master thesis, University of Art, Isfahan, Iran, 2013.

[15] Bemanian M., Application of geometry and proportions in architecture, Tahan, Tehran, Iran, 2011.

[16] Pirniya M., Stylistics of Iranian Architecture, Soroosh Danesh, Tehran, Iran, 2011.

[17] Shahbazishiran H., Major examples of religious buildings of Iran during the Safavid era. Master thesis, Mohaghegh Ardabili University, Ardabil, iran, 2010.

[18] Alipour R., Dehar A., Geometrical analysis of architecture of Sheik Lotfollah Mosque to find the geometrical relations between its prayer hall and the entrance, Bagh-Nazar, 2013, 26, 33-40.

[19] Stierlin H., Image of paradise, Farzanpublishers, Tehran, Iran, 1998.

\section{References}

[1] Aliabadi M., Eternal geometry in Islamic architecture, Journal of Iran University of Science and Technology, 2007, 5, 63-73. 